\title{
Experimental Study of Direct Laser Deposition of Ti-6Al-4V and Inconel 718 by Using Pulsed Parameters
}

\author{
Kamran Shah,, ${ }^{1}$ Izhar U1 Haq, ${ }^{1}$ Shaukat Ali Shah, ${ }^{2}$ Farid Ullah Khan, \\ Muhammad Tahir Khan, ${ }^{1}$ and Sikander Khan ${ }^{1}$ \\ ${ }^{1}$ Institute of Mechatronics Engineering, University of Engineering \& Technology, Peshawar 25100, Pakistan \\ ${ }^{2}$ Mechanical Engineering Department, University of Engineering \& Technology, Peshawar 25000, Pakistan \\ Correspondence should be addressed to Kamran Shah; kamran.shah@nwfpuet.edu.pk
}

Received 31 August 2013; Accepted 27 November 2013; Published 30 January 2014

Academic Editors: D. Hotza and A. Tonkikh

Copyright (C) 2014 Kamran Shah et al. This is an open access article distributed under the Creative Commons Attribution License, which permits unrestricted use, distribution, and reproduction in any medium, provided the original work is properly cited.

\begin{abstract}
Laser direct metal deposition (LDMD) has developed from a prototyping to a single metal manufacturing tool. Its potential for creating multimaterial and functionally graded structures is now beginning to be explored. This work is a first part of a study in which a single layer of Inconel 718 is deposited on Ti-6Al-4V substrate. Single layer tracks were built at a range of powder mass flow rates using a coaxial nozzle and $1.5 \mathrm{~kW}$ diode laser operating in both continuous and pulsed beam modes. This part of the study focused on the experimental findings during the deposition of Inconel 718 powder on Ti-6Al-4V substrate. Scanning electron microscopy (SEM) and X-ray diffraction analysis were performed for characterization and phase identification. Residual stress measurement had been carried out to ascertain the effects of laser pulse parameters on the crack development during the deposition process.
\end{abstract}

\section{Introduction}

Laser direct metal deposition (LDMD) has traditionally been used to build small prototypes and in various applications like component repair [1] and short-run component fabrication [2]. The use of LDMD in the aerospace industry is ever increasing; LDMD of titanium and nickel based alloys is extensively applied to the manufacture of small components and to adding details to large parts [3].

Use of multifunctional materials with significant physical properties difference has seen a growing interest in the past few decades. The functionally graded materials (FGMs) concept has been extended to a variety of materials in various applications [4]. In FGM, composition and properties are customized to suit specific engineering applications [5]. The development of FGMs by laser direct metal deposition has received much attention $[6,7]$. The freedom to selectively deposit different elemental powders at discrete locations using multiple powder feeders makes LDMD well suited to the fabrication of FGMs.

Deposition of dissimilar materials is qualitatively different from similar material deposition for the following reasons: (1) thermophysical properties of the substrate and clad materials are, in general, different, and this difference can influence the heat transfer during deposition; (2) magnitude of stress differs due to the difference in thermal expansion/ contraction properties of the two or more materials; (3) composition becomes a parameter that can vary over a wide range across the melt pool and, consequently, there does not exist a single liquidus isotherm that defines the solid-liquid interface. All layered fabrication processes based on melt deposition, such as laser deposition process, suffer from a residual stress in the final part due to the large temperature gradients between the hot melt zone and the cold substrate [8]. For this reason, there has been very limited work on the deposition of different materials such as nickel and titanium. To avoid sudden change in the composition, a graded structure of Ti-6Al$4 \mathrm{~V}$ and Inconel 718 was carried out by Domack and Baughman [9] using a laser engineered nest shape (LENS) system. The laser used was in a continuous wave mode and powder was fed as premixed powder blends, with the composition adjusted in steps of 10 percent by volume from 100 percent Ti-6Al-4V to 100 percent Inconel 718. Macroscopic cracks formed before the full transition from Ti-6Al-4V to Inconel 718 were achieved but the cause of these was not investigated in any detail in the reported work. In another detailed study 
of a titanium and nickel graded structure by laser deposition, Lin et al. [10] investigated the solidification behaviour and phase evolution of Ti-6Al-4V and Rene 88 DT. All proportions of the constituent alloys were not investigated; the compositional gradient tested ranged from 100 percent Ti-6Al-4V to Ti-6Al-4V with 38 percent Rene 88 DT. In all of the previous studies on nickel and titanium, the effects of generation of transient/residual stresses have largely been ignored.

To date, the generation of residual stresses has received relatively little attention. Few authors [11-14] have used neutron diffraction techniques in stainless steel and Inconel 718 laser deposited thin walls and thick pillars. X-ray diffraction technique $[15,16]$ can also be used to measure residual stresses. When using conventional X-ray diffraction techniques, depth of penetration of the X-ray beam, based on the use of standard copper, iron, chromium, and cobalt anodes, is limited to $(3 \pm 10 \mathrm{~mm})$ and hence only residual stresses along the surface region can be determined accurately. To obtain stresses at greater depths, removal of material by chemical etching or electric discharge machine (EDM) is necessary.

Previous studies show that functional grading of titanium and nickel alloys cannot provide a complete solution to the problem of stress cracking and hence, in this work, a different approach has been investigated. Here, instead of gradual change in the composition of the Ti-6Al-4V and Inconel 718, deposition of pure Inconel 718 on top of Ti-6Al-4V substrate has been carried out by employing two different modes of laser beam, continuous and pulsed, and different pulse parameters. These two modes produce different thermal gradients which could reduce the transient and hence the residual stresses in the final part. In addition, various powder mass flow rates have been tested to investigate the effect of mass addition on the susceptibility to stress cracking.

\section{Experimental Procedure}

A series of experiments were performed to investigate single layer laser deposition of Inconel 718 on Ti-6Al-4V substrate. Schematic of the process is shown in Figure 1. Two sets of samples for each parameters combination were used in order to analyze the effect of diode laser pulse parameters and powder flow rate, with varying pulse length and period. Inconel 718 powder was deposited on a Ti-6Al-4V substrate. The substrates were machined into $48 \times 50 \times 11 \mathrm{~mm}$ rectangular coupons. These substrates were first sand blasted in a Guyson sand blaster and then degreased using ethanol to aid deposit adhesion. In this study, 9 samples were produced. A $1.5 \mathrm{~kW}$ Laserline LDL 160-1500 diode laser, producing approximately equal amounts of 808 and $940 \mathrm{~nm}$ laser radiation operated in either continuous or pulsed mode, was used to carry out the experiments. The beam size was experimentally measured by exposing an infrared detector card with a sensitivity of $1.75 \times 10^{-9} \mathrm{~W} / \mathrm{mm}^{2}$ to the pilot beam $(20 \mathrm{~mW})$ of the diode laser and was found to be $1.67 \mathrm{~mm}$ with top hat (approximately uniform) power distribution.

The absorptivity of diode laser wavelengths (808 and $940 \mathrm{~nm}$ ) was measured using a SD2000 fibre optic spectrometer which was $45 \sim 51 \%$. The substrate was tightly secured on

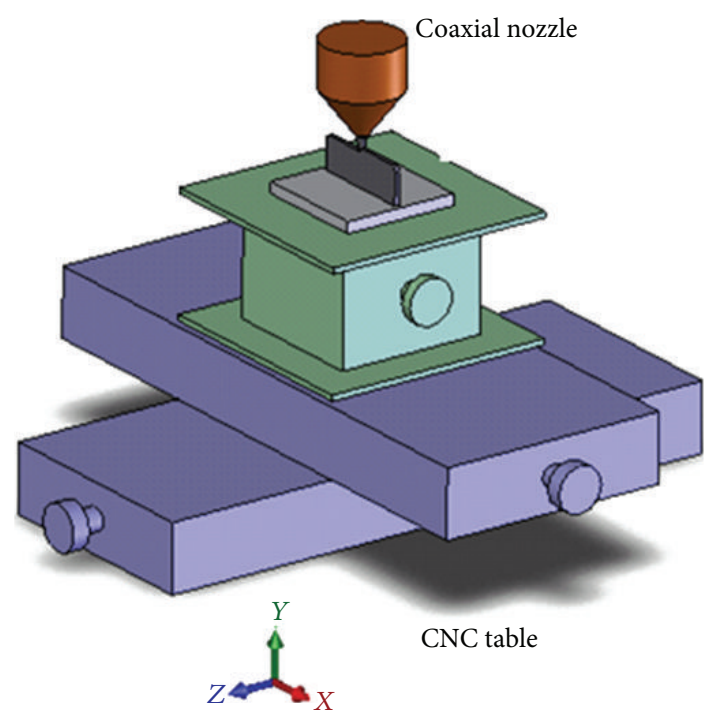

FIGURE 1: Schematic of the LDMD process.

a clamp and then mounted onto a 3-axis position and motion control system. Inconel 718 powder was gas atomised, giving particles with approximately spherical morphology, and had a powder size distribution of $53-150 \mu \mathrm{m}$. A disc-type powder feeder was used to deliver them to the nozzle. The deposition area was also shrouded by an Argon gas flow from a coaxial nozzle directed at the melt pool. The gas pressure for all the experiments was set at 5 bars. A velocity of $4 \mathrm{~mm} / \mathrm{s}$ was maintained during the deposition of all the samples.

Parameters were varied specifically to enable the study of the effect of powder flow rate and the duty cycle. A mean power of $600 \mathrm{~W}$ was used as established from previous experiments. This provided a specific energy appropriate for the deposition of both Inconel 718 and Ti-6Al-4V at the chosen traverse speed and beam area and was kept constant throughout. The experimental parameters used are shown in Table 1.

After the experiments, uncracked samples were held in a fixture on HURCO 425 Mark 2 sink type spark erosion electric discharge machine (EDM). Samples were longitudinally machined till they reached the middle of the clad by using copper as a tool electrode.

After machining the samples, residual stresses on one set of uncracked deposited tracks (S1-S3) were measured using X-ray diffraction technique, based on $\sin 2 \psi$ method [17] which uses the planes of crystal lattice as an atomic scale "strain gauge." X-ray residual stress analysis is based on the angular shift of diffraction lines due to stresses [18].

A Bruker AXS D8 Discover laboratory X-ray diffractometer was used. This equipment has a polycapillary optics $\mathrm{X}$-ray beam and general area detector diffraction system (GADDS) detector collecting backscattered X-ray DebyeScherrer cones. An iron anode X-ray tube $(\lambda=1.9360 \AA)$ at $30 \mathrm{kV}$ and $20 \mathrm{~mA}$ was used and the 311 diffraction peak was recorded at a " $2 \theta^{\prime}$ " angle of about $128^{\circ} .10 \psi$ values, from 0 to 45 degrees, were used for each point, giving a data collection time of 200 seconds for each $\theta$ value. Young's modulus value of $200 \mathrm{GPa}$ and Poisson's ratio value of 0.30 [19] were used to calculate residual stresses. 
TABLE 1: Experimental parameters used in the experiment.

\begin{tabular}{|c|c|c|c|c|c|}
\hline Sample no. & Peak power $(\mathrm{W})^{\mathrm{A}}$ & Pulse length (ms) & Period (ms) & Duty cycle $^{\mathrm{B}}$ & Powder mass flow rate $(\mathrm{g} / \mathrm{s})$ \\
\hline 1 & 1500 & 20 & 50 & 0.4 & 0.358 \\
\hline 2 & 857 & 35 & 50 & 0.7 & 0.358 \\
\hline 3 & 600 & - & - & 1 & 0.358 \\
\hline 4 & 1500 & 20 & 50 & 0.4 & 0.586 \\
\hline 5 & 857 & 35 & 50 & 0.7 & 0.586 \\
\hline 6 & 600 & - & - & 0.1 & 0.586 \\
\hline 7 & 1500 & 20 & 50 & 0.4 & 0.674 \\
\hline 8 & 857 & 35 & 50 & 0.7 & 0.674 \\
\hline 9 & 600 & - & - & 1 & 0.674 \\
\hline
\end{tabular}

${ }^{\mathrm{A}}$ Mean power $=600 \mathrm{~W}$ in all cases; ${ }^{\mathrm{B}}$ duty cycle $=$ pulse length $/$ period.

$\mathrm{X}$-ray diffraction phase analyses were carried out using a Philips X'Pert MPD X-ray diffractometer with a $\mathrm{Cu}$ anode to provide radiation of $1.5405 \AA$ wavelength. For each sample, the deposited tracks were separated from the substrate and the interface was scanned between $2 \theta$ angles of 0 and 85 degrees with a 30 -second scan step time. To perform the Xray diffraction phase analysis, samples 1,2 , and 3 were broken from the substrates, forcefully if necessary. X-ray diffraction phase analyses were then carried out on the bottom side of clad and on the top of the substrate where individual tracks were deposited. After stress analysis, the other set of uncracked samples were transversely sectioned and mounted in Struers epoxy resin. All samples were polished to $\mathrm{Ra}=1 \mu \mathrm{m}$ using standard metallographic techniques. The samples were electrolytically etched in $10 \%$ oxalic acid to reveal the microstructure. These microstructures were then evaluated using a Hitachi High Technologies, S-3400N Type I, 0-30 kV scanning electron microscope.

\section{Results}

3.1. Macrostructure and Visible Cracking. Examination of the final Ti-6Al-4V and Inconel 718 structures showed that only three out of the nine samples were crack-free. Sample 1 (0.4 duty cycle, low powder mass flow rate), sample 2 (0.7 duty cycle, low powder mass flow rate), and sample 3 (continuous wave, low powder mass flow rate) showed no signs of cracking. All other samples developed severe cracks initiated at the interface of the clad and the substrate. Cross section of cracked interface of sample 4 is shown in Figure 2.

3.2. Phase Analysis Using X-Ray Diffraction. Different phases constitute the microstructure of the melt pool and these are identified from the composition analyses using X-ray diffraction. In this work, despite the small size of the samples, clear spectra with well-defined diffraction peaks were obtained. Figure 3 shows X-ray diffraction spectra for all the samples. The XRD patterns for all the samples look very similar except in sample 6 which reveals the presence of $\mathrm{TiNi}_{3}$. All these results indicate the presence of $\mathrm{Ti}_{2} \mathrm{Ni}$ and $\mathrm{Ti}$ in all of the samples. Quantification of the phases present was not possible.

3.3. Residual Stress Results. Uncracked samples were machined in a $y-z$ plane as shown in Figure 4. Line scans were

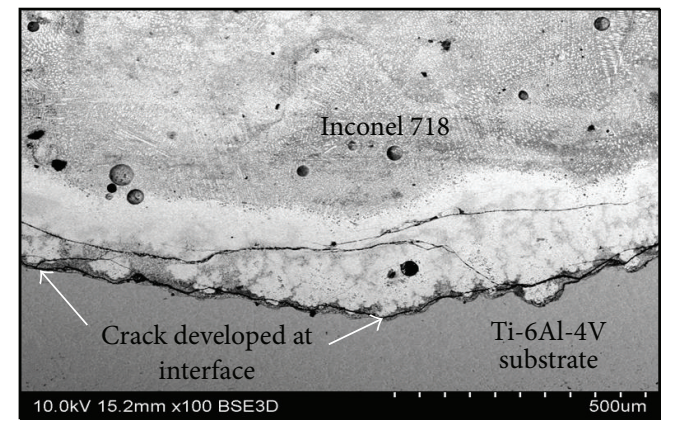

FIgURE 2: Cracked interface between Ti-6Al-4V and Inconel 718 in sample 4 .

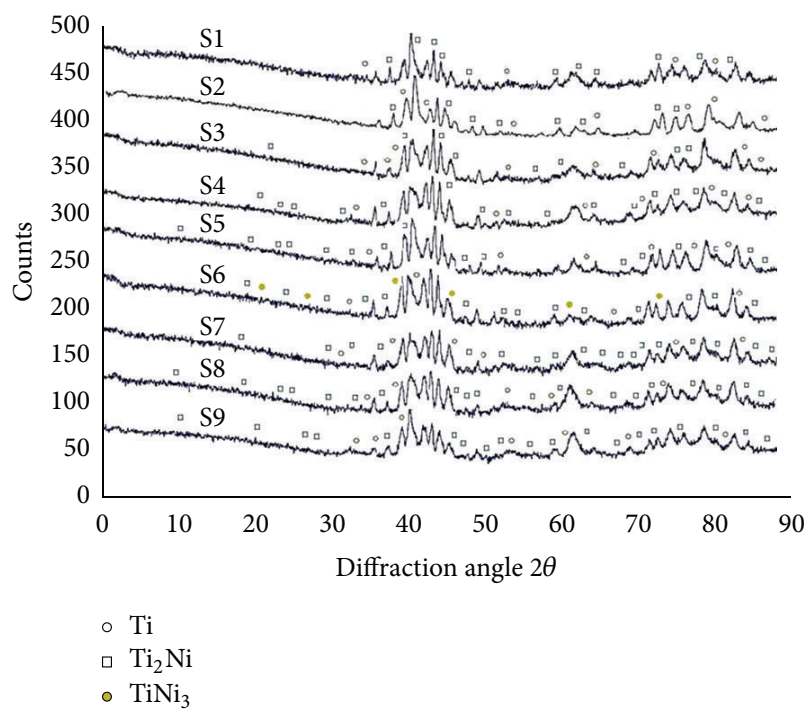

FIGURE 3: XRD diffraction patterns showing the presence of various phases.

carried out to measure vertical " $\sigma_{y y}$ " and longitudinal " $\sigma_{z z}$ " residual stresses in the middle of the clad and along the track length of uncracked samples 1-3. The measured distributions are plotted for three different duty cycle depositions in Figures 5, 6, and 7, respectively. 


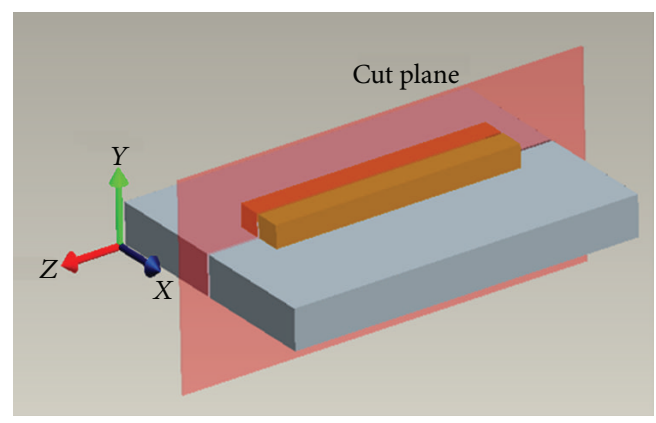

FIgURE 4: Substrate and clad geometry.

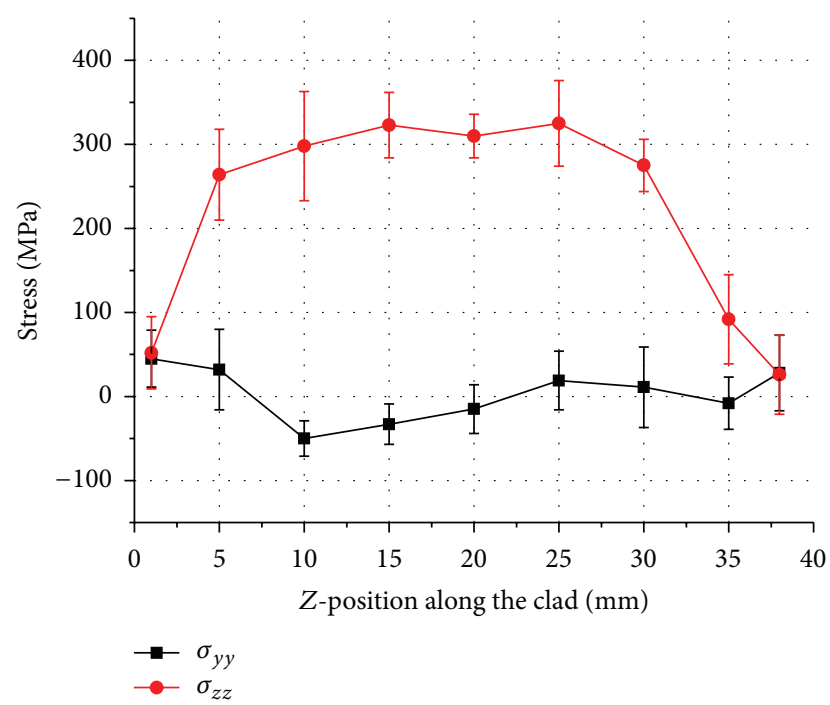

FIGURE 5: Stress result in sample 1, 0.4 DC pulsed laser deposition.

Figures 5-7 show an approximately parabolic distribution of residual stresses in the $z$-direction with a maximum calculated stress close to the centre position. There is more variation in stress values in case of pulsed deposition as compared to the continuous wave deposition. Increase in tensile stresses in longitudinal direction with the increase in duty cycle is also noted. A maximum tensile stress " $\sigma_{z z}$ " value of $583 \mathrm{MPa}$ is observed in the continuous wave deposition midway along the clad and residual stress of approximately $0 \mathrm{MPa}$ at the ends of the tracks. Stress " $\sigma_{y y}$ " is seen to be compressive along the clad length in all three samples, with the exception of ends of the deposited clad where low levels of tensile residual stresses are obtained.

\section{Discussion}

Factors which can cause deposited clads to crack can be divided into metallurgical and mechanical factors. Metallurgical factors mainly concern phase relationships, while mechanical factors are related to stress behaviour.

Considering metallurgical factors, XRD results show the presence of $\mathrm{Ti}_{2} \mathrm{Ni}$ and $\mathrm{TiNi}_{3}$ in all of samples whether cracked or uncracked. $\mathrm{Ti}_{2} \mathrm{Ni}$ and $\mathrm{TiNi}_{3}$ are recognized as one of the

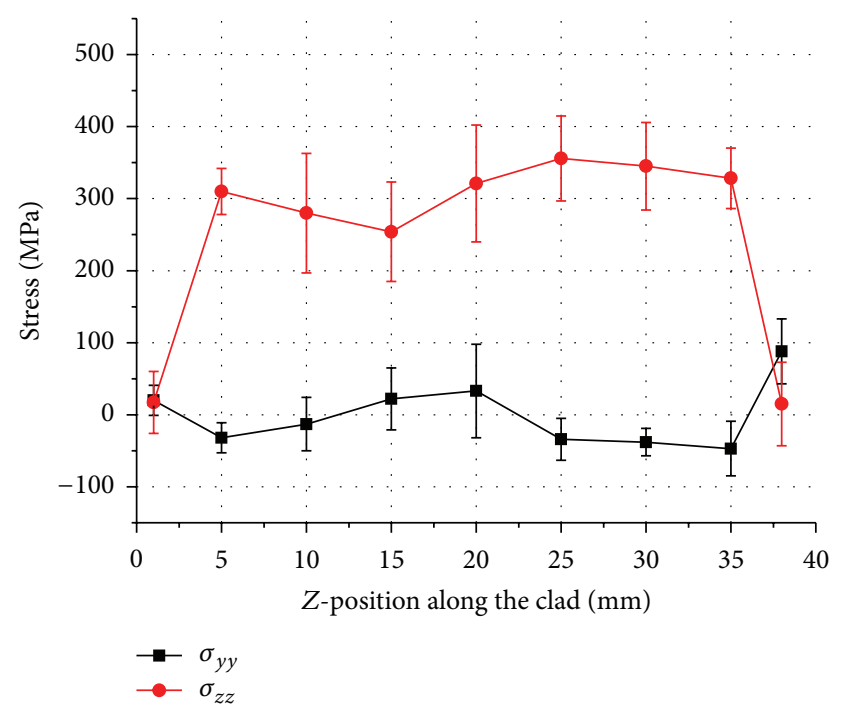

FIGURE 6: Stress result in sample 2, 0.7 DC pulsed laser deposition.

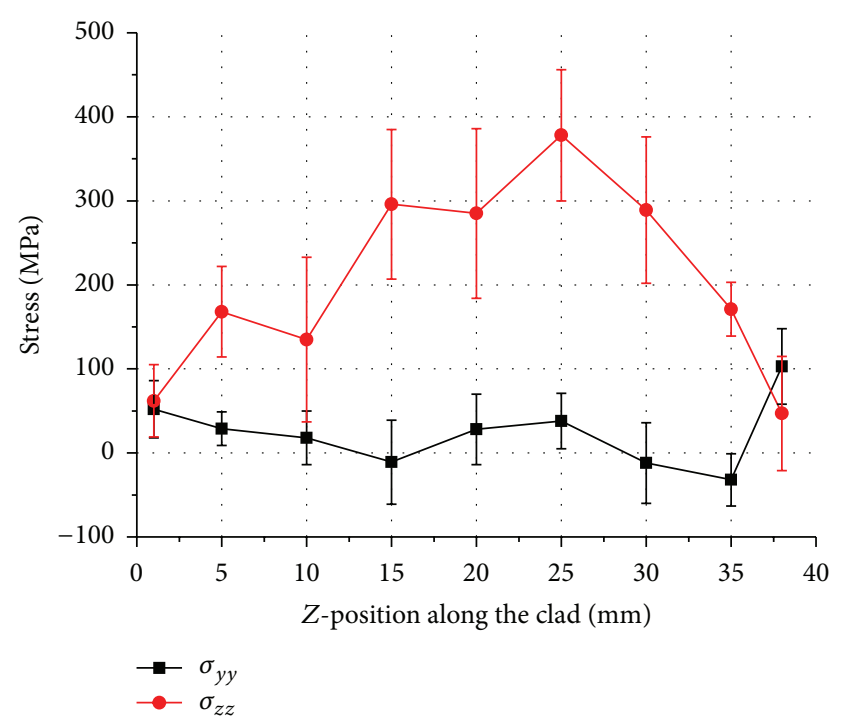

FIGURE 7: Stress result in sample 3, continuous wave laser deposition.

brittle phases responsible for cracking in welding and their presence in all samples suggests that an appropriate selection of laser parameters may not be sufficient to avoid the production of such intermetallics.

Taking into account the mechanical factors, stresses can be generated by constrained elastic expansion or contraction due to transient temperature gradients, and thermal expansion coefficient mismatch, and changes in specific density due to solid phase transformations. The amount of heat input determines the cooling rate, which is inversely proportional to the square of the melt pool length [20]. Thermal strains caused by high cooling rates can increase the crack initiation rate, but higher thermal gradients result in a rapid cooling rate and as, has been shown previously in case of a weld, can also reduce the grain size to increase solidification and crack resistance [21]. 
Results presented here suggest that the trend in residual stresses generated during the deposition of Inconel 718 by either pulsed or continuous beam does not vary significantly apart from the continuous wave deposition which exhibits a comparatively higher residual stress in the longitudinal direction. This can be explained by the fact that the cooling rate for the continuous wave deposition samples is higher as shown by the clad width. Consequently, a larger proportion of residual stress in longitudinal direction is observed as compared to the shorter pulse length or low duty cycle samples. This kind of conclusion is also reported by Moat et al. [14] who found large tensile longitudinal stresses at the mid position of the wall. The vertical stresses " $\sigma_{y y}$ " are tensile near the vertical free surfaces which are balanced by the compressive stresses in the interior of the track.

It is observed that the stresses developed during low powder feed rate deposition (continuous and pulsed) are less than the yield strength of either of the two materials (Inconel 718 and Ti-6Al-4V) and the phases which are present in the samples are also similar. The measurement of residual stresses in this work is limited only to low powder deposition. It is necessary, however, to establish the transient behaviour of stresses generated during the medium and high powder mass flow rate deposition. Numerical modelling of the deposition process may provide the best means of estimating these stresses.

\section{Conclusions}

Various pulse parameters for a diode laser have been used to exploit the effects of direct laser metal deposition of Inconel 718 on Ti-6Al-4V substrate. The driver for this study is to understand and analyse the deposition of Inconel 718 and Ti$6 \mathrm{Al}-4 \mathrm{~V}$ by examining the stress fields and phases evolved during LDMD. XRD techniques have been utilized for the residual stresses and phases generated during the deposition process. It has been found that two brittle phases, that is, $\mathrm{Ti}_{2} \mathrm{Ni}$ and $\mathrm{TiNi}_{3}$, are produced during the deposition of all of the samples. It has also been observed that high longitudinal tensile stresses are developed along the tracks during the deposition process and increase with the duty cycle. The effect of duty cycle on residual stresses in low powder deposition process is, nevertheless, inconclusive and makes it difficult to explain the crack initiation.

\section{Conflict of Interests}

The authors declare that there is no conflict of interests regarding the publication of this paper.

\section{References}

[1] K. Yamada, S. Morisita, M. Kutsuna, and T. Ikeda, "Direct diode laser cladding of Co based alloy to dual phase stainless steel for repairing the machinery parts," in 1st International Symposium on High-Power laser Macroprocessing, vol. 4831 of Proceedings of SPIE, pp. 65-70, Osaka, Japan, May 2002.

[2] D. Krantz, S. Nasla, J. Byrne, and B. Rosenberger, "On-demand spares fabrication during space missions using laser direct metal deposition," AIP Conference Proceedings, vol. 552, pp. 170-175, 2001.

[3] S. Y. Gao, Y. Z. Zhang, L. K. Shi, B. L. Du, M. Z. Xi, and H. Z. Ji, "Research on laser direct deposition process of Ti-6Al-4V alloy," Acta Metallurgica Sinica (English Letters), vol. 20, no. 3, pp. 171180, 2007.

[4] M. Koizumi, "FGM activities in Japan," Composites B, vol. 28, no. 1-2, pp. 1-4, 1997.

[5] W. Liu and J. N. DuPont, "Fabrication of functionally graded $\mathrm{TiC} / \mathrm{Ti}$ composites by laser engineered net shaping," Scripta Materialia, vol. 48, no. 9, pp. 1337-1342, 2003.

[6] Y. T. Pei and J. T. M. de Hosson, "Functionally graded materials produced by laser cladding," Acta Materialia, vol. 48, no. 10, pp. 2617-2624, 2000.

[7] E. Yarrapareddy, S. Zekovic, S. Hamid, and R. Kovacevic, “The development of nickel-tungsten carbide functionally graded materials by a laser-based direct metal deposition process for industrial slurry erosion applications," Proceedings of the Institution of Mechanical Engineers B, vol. 220, no. 12, pp. 1923-1936, 2006.

[8] N. W. Klingbeil, J. L. Beuth, R. K. Chin, and C. H. Amon, "Residual stress-induced warping in direct metal solid freeform fabrication," International Journal of Mechanical Sciences, vol. 44, no. 1, pp. 57-77, 2002.

[9] M. S. Domack and J. M. Baughman, "Development of nickeltitanium graded composition components," Rapid Prototyping Journal, vol. 11, no. 1, pp. 41-51, 2005.

[10] X. Lin, T. M. Yue, H. O. Yang, and W. D. Huang, "Solidification behavior and the evolution of phase in laser rapid forming of graded Ti6Al4V-Rene88DT alloy," Metallurgical and Materials Transactions A, vol. 38, no. 1, pp. 127-137, 2007.

[11] L. Wang, S. D. Felicelli, and P. Pratt, "Residual stresses in LENSdeposited AISI 410 stainless steel plates," Materials Science and Engineering A, vol. 496, no. 1-2, pp. 234-241, 2008.

[12] P. Pratt, S. D. Felicelli, L. Wang, and C. R. Hubbard, "Residual stress measurement of laser-engineered net shaping AISI 410 thin plates using neutron diffraction," Metallurgical and Materials Transactions A, vol. 39, no. 13, pp. 3155-3163, 2008.

[13] P. Rangaswamy, T. M. Holden, R. B. Rogge, and M. L. Griffith, "Residual stresses in components formed by the laser-engineered net shaping (LENS) process," Journal of Strain Analysis for Engineering Design, vol. 38, no. 6, pp. 519-527, 2003.

[14] R. J. Moat, A. J. Pinkerton, D. J. Hughes, L. Li, P. J. Withers, and M. Preuss, "Stress distributions in multilayer laser deposited Waspaloy parts measured using neutron diffraction," in Proceedings of the 26th International Congress on Applications of Lasers and Electro-Optics (ICALEO '07), Orlando, Fla, USA, November 2007.

[15] U. de Oliveira, V. Ocelík, and J. T. M. de Hosson, "Residual stress analysis in co-based laser clad layers by laboratory X-rays and synchrotron diffraction techniques," Surface and Coatings Technology, vol. 201, no. 3-4, pp. 533-542, 2006.

[16] A. J. Pinkerton, J. Shackleton, R. Moat et al., "The effect of process parameters on residual stresses within an inconel 718 part produced by the direct laser deposition process," in Proceedings of the 24th International Congress on Applications of Lasers and Electro-Optics (ICALEO '05), pp. 601-610, Laser Institute of America, Miami, Fla, USA, November 2005.

[17] B. Cullity, Elements of X-Ray Diffraction, Reading, Mass, USA, Addison-Wesley edition, 1978.

[18] B. E. Warren, X-Ray Diffraction, Dover, New York, NY, USA, 1969. 
[19] M. J. Donachie and S. J. Donachie, Superalloys: A Technical Guide, ASM International, 2002.

[20] W. Hofmeister and M. Griffith, "Solidification in direct metal deposition by LENS processing," JOM, vol. 53, no. 9, pp. 30-34, 2001.

[21] H. Zhao, D. R. White, and T. Debroy, "Current issues and problems in laser welding of automotive aluminum alloys," International Materials Reviews, vol. 44, no. 6, pp. 238-266, 1999. 

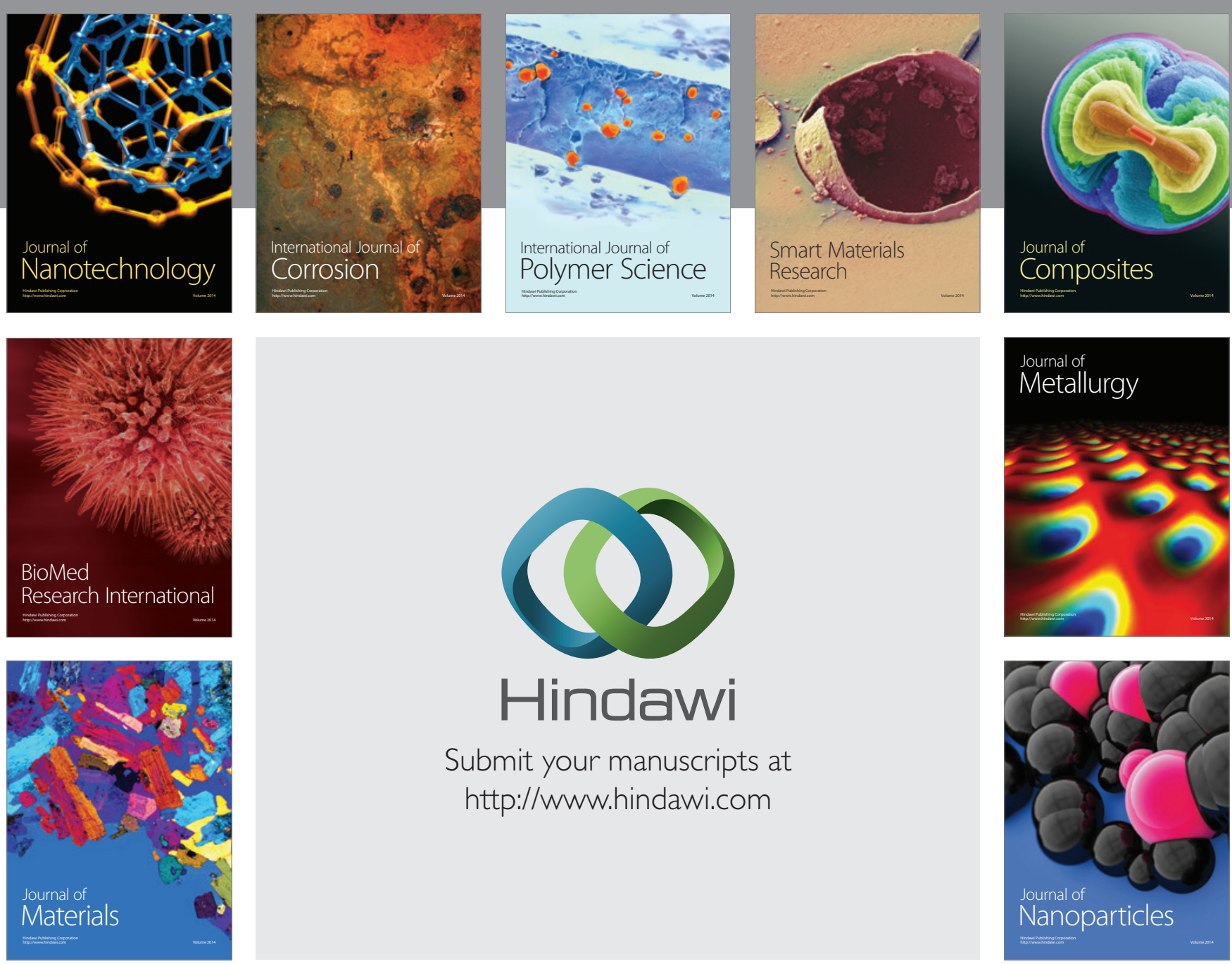

Submit your manuscripts at http://www.hindawi.com
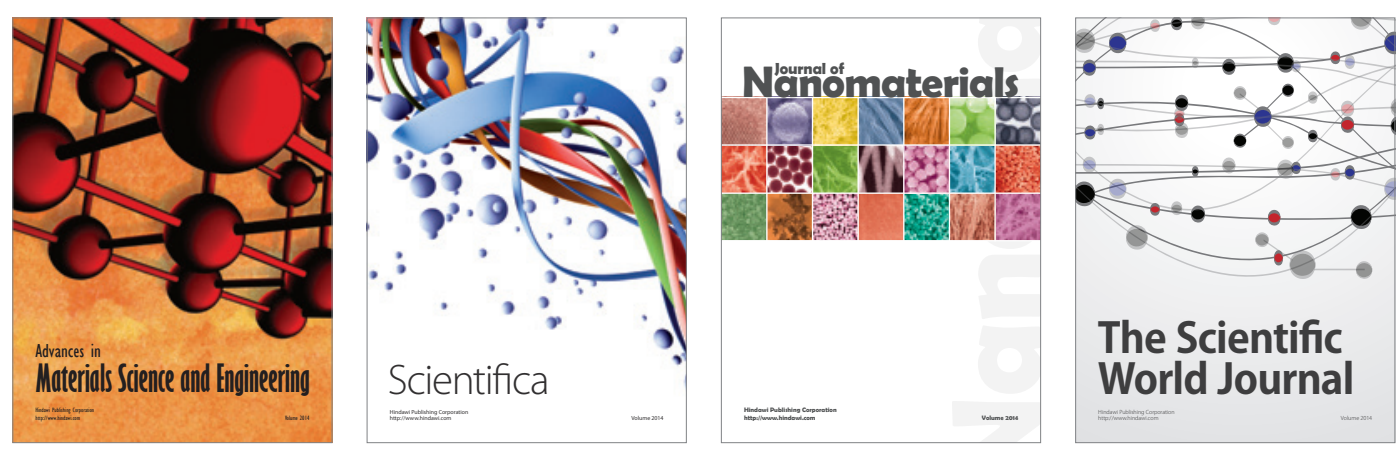

\section{The Scientific World Journal}
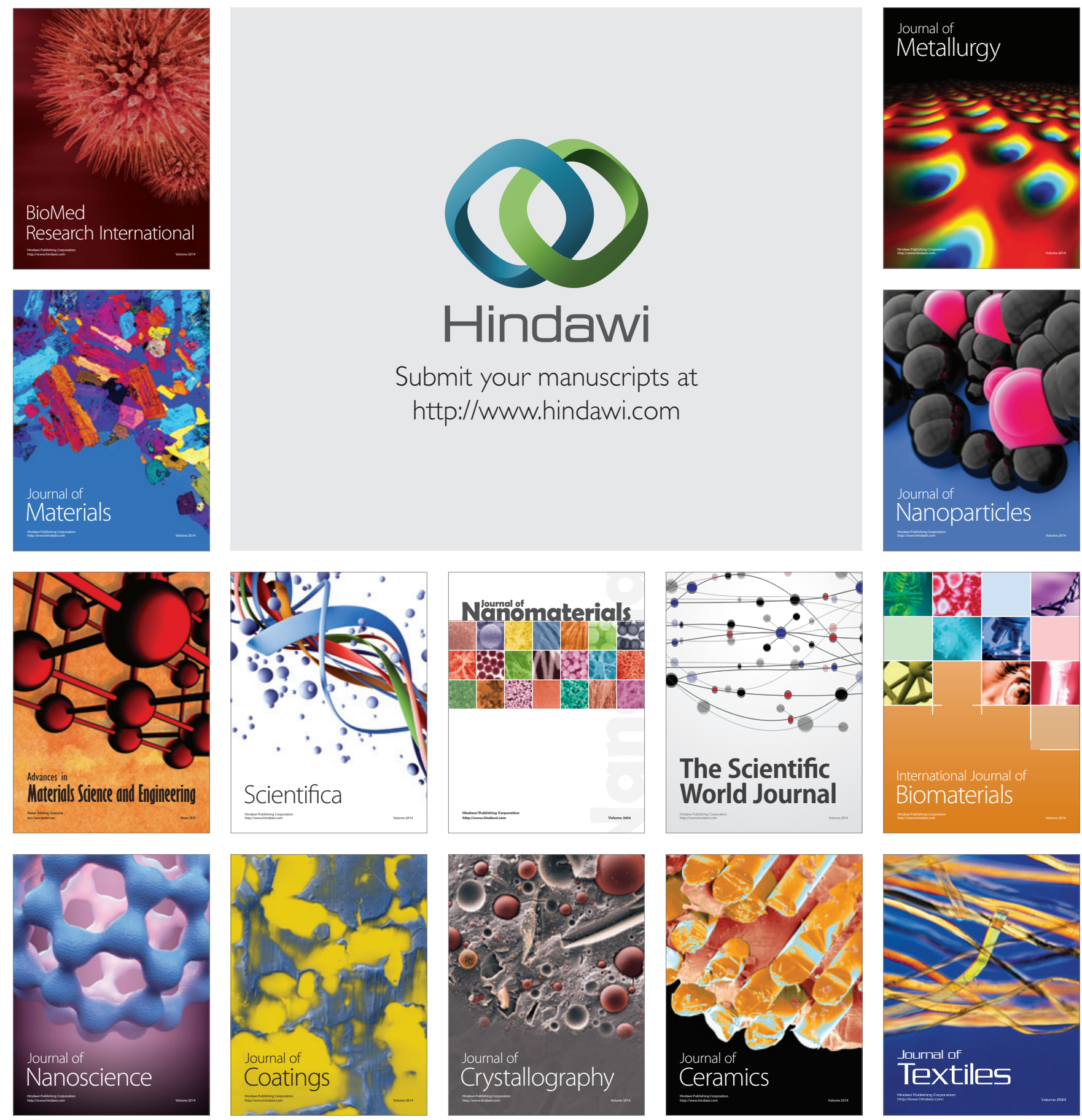